Вестник ВГУ. Серия: Право

УДК 347

DOI https://doi.org/10.17308/vsu.proc.law.2020.3/2976

\title{
«НОВОЕ» КОРПОРАТИВНОЕ РЕГУЛИРОВАНИЕ: РАСШИРЕНИЕ СФЕРЫ ДЕЙСТВИЯ КОРПОРАТИВНЫХ АКТОВ
}

\author{
О. В. Фонотова \\ Национальный исследовательский университет \\ "Высшая школа эконолики" \\ Поступила в редакцию 25 декабря 2019 г.
}

\begin{abstract}
Аннотация: предлагается расслатривать корпоративное регулирование в более широкол, чел традииионный, контексте. Выдвигается следующая гипотеза для правового исследования: наряду с традиционныл пониманиел, ограничивающил корпоративное регулирование сфберой "внутреннего" взаилодействия корпорации и ее участников, органов и наелных работников, корпоративное регулирование следует расслатривать расширительно, т. е. как вид "внешнего" воздействия, оказываелого корпорацией на правоотношения с другили лицали: контрагентали по договорал, цепочкали поставщиков, подрядчиков и покупателей, потенциальнылии деловыли партнерами, инылии представителяли сообщества, в котором корпорация ведет деятельность. На базе обобщения научных мнений о сущности негосударственного регулирования в частнол праве (часть 1) автор фборлулирует подход к расширительнолу толкованию корпоративного регулирования как вида негосударственного регулирования частных правоотношений (часть 2). Далее рассматривается разнообразие корпоративных актов, т. е. фборл, в которых выражается корпоративное регулирование (часть 3). Статья завершается постановкой проблелных вопросов, связанных с воздействиел корпоративного регулирования на частные правоотношения (часть 4). Проводится ревизия терлинологической базы корпоративного регулирования, отлечается потребность в упорядочении правового словаря и обосновывается необходимость использования, взален илеющихся разрозненных обозначений, следующих терлинов: "негосударственное регулирование», "корпоративное регулирование", "корпоративные акты"».

Ключевые слова: негосударственное регулирование, негосударственное право, корпоративное регулирование, корпоративные акты.
\end{abstract}

116 Abstract: the author suggests taking a broader view on corporate regulation. The following thesis is being put forward for a legal research: in addition to the traditional approach which limits the scope of corporate regulation by «internal" relations involving corporation, its shareholders, corporate bodies and employees, corporate regulation has to be approached in a broader sense, i.e., in the context of an "external" impact caused by a corporation on its relations with other persons: contractual counterparties, supply chains actors, contractors and clients, potential business partners, other representatives of the social environment where the corporation carries its activities. Starting with generalization of doctrinal views on the essence of nonstate regulation in private law (in part 1), the author then forms an approach towards a broad interpretation of corporate

(C) Фонотова О. В., 2020 


\section{Гражданское право. Гражданский процесс. Арбитражный процесс}

regulation as a type of nonstate regulation of private legal relations (in part 2). The article then considers the variety of forms in which corporate regulation is expressed, i.e., corporate acts (in part 3), and concludes with the statement of problem issues which arise in connection with the influence exerted by corporate regulation on private law relations (in part 4). A revision of traditional terminological base has been undertaken throughout the text. The research has shown that the legal dictionary of corporate law needs to be streamlined and brought to order. With an aim to improve the existing discordant terminology, the use of the following concise terms has been justified: "nonstate regulation", "corporate regulation", "corporate acts".

Key words: nonstate regulation, nonstate law, corporate regulation, corporate governance, corporate acts.

Корпоративное регулирование как правовой френомен является предметом повышенного внимания ученых и практикующих юристов. Дискуссии о воздействии корпораций на общественные отношения в частноправовой сфере, порой перетекающие в настоящие баталии, ведутся на страницах зарубежной научной прессы не один десяток лет ${ }^{1}$. Интерес к негосударственным способам регулирования частноправовых отношений усиливается и в отечественной правовой доктрине, о чем свидетельствует стремительно растущее число фундаментальных научных исследований и публикаций.

Вправе ли корпорация создавать право? Насколько далеко может зайти влияние корпорации на лиц, формально не связанных с ней договором, участием в уставном капитале? Каким образом корпорации формируют деловую практику? В силу действия каких механизмов одна корпорация устанавливает правила поведения, по которым «живет» отрасль экономики? А если таких корпораций в индустрии несколько, как следует разрешать конфликт между правилами, созданными этими субъектами? Как на указанное регулирование реагирует государство? Практика делового оборота все чаще требует ответов на вопросы, которые еще не осмыслены ни законодателем, ни судебными инстанциями, ни даже более скорым на реакцию юридическим сообществом.

Целью данной работы является обоснование использования в научном и деловом обороте категории «корпоративное регулирование» в более широком понимании, чем традиционно сводимое к регулированию внутрикорпоративных отношений. В статье развивается следующий тезис: корпоративное регулирование на современном этапе необходимо рассматривать расширительно, в том числе как вид негосударственного нормативного регулирования отношений корпорации и лиц, внешних по отношению к корпорации. Прежде чем искать подходы к новому для частного права материалу и давать ему правовую оценку, необходимо определиться с исходными понятиями.

${ }^{1}$ Актуальный обзор взглядов западных ученых на проблему негосударственного права представлен М. В. Мажориной (см.: Мажорина М. В. Международное частное право в условиях глобализации : от разгосударствления к фрагментации // Право. Журнал Высшей школы экономики. 2018. № 1. С. 193-217). 


\section{Вестник ВГУ. Серия: Право}

\section{Негосударственное регулирование частноправовых отношений}

Регулирование - весьма распространенная категория для общественных наук. Термин широко используется в экономике, политологии, праве. Несмотря на его сопутствие правовому обиходу, единый подход к пониманию регулирования как правового феномена в современных публикациях не прослеживается.

Что означает регулировать? В русский язык слово пришло из латыни, оно производно от латинского regula - правило. В толковании Д. Н. Ушакова регулировать значит упорядочивать, направлять что-нибудь, воздействовать на что-нибудь с целью внести порядок, правильность ${ }^{2}$. Согласно С. И. Ожегову, регулировать - это к тому же налаживать, приводить в такое состояние, которое обеспечивает нормальную и правильную работу․․ Таким образом, с точки зрения коммуникативного аспекта регулирование общественных отношений сводится к деятельности по их упорядочению и поддержанию порядка с помощью правил.

Экономическая трактовка термина укладывается в указанные семантические рамки: «регулировать» значит подчинять определенному порядку, правилу, упорядочивать ${ }^{4}$. Это понятное конвенциональное толкование, которое не вызывает споров среди экономистов.

Регулирование имманентно праву. Редкое юридическое изыскание может обойтись без ссылок на него, но нередко термин «регулировать» употребляется инерционно, необдуманно. Общим местом стало определение регулирования, предлагаемое в справочных изданиях, как процесса целенаправленного воздействия государства на общественные отношения $^{5}$. В целом, в литературе правовое регулирование обычно отождествляется с формой осуществления функции государства.

К огромному сожалению, в российской юриспруденции сложилось понимание регулирования как властной деятельности государства по созда-

으 нию нормативных правил поведения, т. е. произошла подмена понятий, при которой весь объем правового регулирования оказался сведенным к государственному регулированию. Такой подход можно объяснить следованием традиции правового позитивизма, что для частноправового дискурса неприемлемо. Отношение к правовому регулированию как к ис-

118 ключительно государственной деятельности не способствует постижению сути тех явлений и событий, которые происходят в повседневной деловой практике.

Чем, если не регулированием, служат правила фондовой биржи для компаний, претендующих на листинг? Почему всякий потенциальный

${ }^{2}$ См.: Ушаков Д. Н. Большой толковый словарь современного русского языка. M., 2008.

${ }^{3}$ См.: Ожегов С. И. Толковый словарь русского языка. М., 2009.

${ }^{4}$ См.: Райзберг Б. А., Лозовский Л. Ш., Стародубиева Е. Б. Современный экономический словарь. М., 2011. URL: http://www.consultant.ru/document/cons_ doc_LAW_67315/ (дата обращения: 25.12.2019).

${ }^{5}$ См.: Большой юридический словарь / В. Н. Додонов [и др.]. М., 2001. 
Гражданское право. Гражданский процесс. Арбитражный процесс

поставщик товаров в крупную торговую сеть должен пройти несколько этапов проверок, прежде чем ему будет предоставлена возможность начать переговоры по поводу поставки? Как объяснить повсеместное заключение коммерческих договоров по типовым формам, разработанным компаниями?

В зависимости от субъекта - источника регулирования в экономике выделяют государственное регулирование и саморегулирование (негосударственное регулирование). В самых общих чертах под государственным регулированием понимается воздействие, оказываемое государством, а саморегулирование представляет собой регулирование, осуществляемое участниками рынка. Регулирование не сводится исключительно к модели власти-подчинения, когда инструкция «спускается» регулирующим государственным органом тем, на кого направлено такое воздействие. За хозяйствующими субъектами признается способность самостоятельно формировать правила поведения.

Как было показано, термин «регулирование» не наделен властным смысловым подтекстом, он обозначает лишь механизм (метод, способ, процесс) воздействия на общественные отношения. Удачное определение было предложено еще в советское время С. С. Алексеевым. Ученый трактует правовое регулирование как «осуществляелое при помощи правовых средств ... результативное, норлативно-организационное воздействие на общественные отношения в целях их упорядочения, охраны, развития в соответствии с общественными потребностями» ${ }^{6}$.

Для частноправового исследования XXI в. важно разграничивать два уровня регулирования: государственное и негосударственное. Государственное правовое регулирование традиционно представлено всем объемом правовых норм, авторство которых принадлежит государству. Негосударственное регулирование исходит не от государства (отсюда и термин), а создается субъектами частного права в процессе их деятельности (государство может участвовать в формировании негосударственного регулятивного материала, если оно выступает в качестве субъекта частного права). Подходы к изучению двух данных направлений существенно разнятся; методы и способы познания государственных установлений не годятся для изучения негосударственных регуляторов.

На существование негосударственного регулирования как регулятивного массива негосударственного происхождения впервые в российском праве обратил внимание видный специалист в области международного торгового права И. С. Зыкин. Он рассматривает данное явление как правовое, способное оказывать регулирующее воздействие (при определенных обстоятельствах), но не относящееся к обязывающим государственным предписаниям. Ученый уделяет основное внимание реальному, эфрективному воздействию, оказываемому теми или иными негосударственными установлениями на общественные отношения, призывает юристов исследовать регулирование, которое не исходит непосредствен-

${ }^{6}$ Алексеев С. С. Общая теория права : в 2 т. М., 1981. Т. 1. С. 289. 


\section{Вестник ВГУ. Серия: Право}

но от государства, хотя и допускается им. Ученый ратует за то, что именно такой фрункциональный подход в правовых исследованиях поможет преодолеть разрыв между правом и практикой ${ }^{7}$.

И. С. Зыкин совершенно верно отмечает, что обособление негосударственного и государственного регулирования не является самоцелью, а лишь служит лучшему уяснению правовой действительности. Внимание автора ориентировано на международно-правовую среду, но при этом он сам признает, что результаты его исследования могут быть применены и в области регулирования внутренних деловых отношений, в том числе в рамках отечественного правопорядка.

Доктринальная база, созданная И. С. Зыкиным четверть века назад, активно дополняется и развивается в настоящее время. Частноправовая проблематика негосударственного регулирования в контексте международного частного права получила развитие в научной деятельности А. С. Комарова, Н. Г. Вилковой, С. В. Бахина, В. А. Канашевского, А. В. Демина, М. В. Мажориной, А. А. Дьяконовой, Е. В. Ломакиной, Я. О. Алимовой и др. Среди исследователей отечественного правопорядка следует выделить Б. И. Пугинского, И. Г. Вахнина, Р.-М. З. Зумбулидзе, А. И. Поротикова, Ю. Б. Фогельсона, М. М. Панариной, посвятивших свои труды негосударственным регуляторам частноправовых отношений и высоко оценивших их эффрективность и потенциал.

В литературе можно встретить множество наименований негосударственных регуляторов: мягкое право (soft law), субправо, транснациональное право, новое lex mercatoria, право торговцев, право без государства, третий правопорядок и др. ${ }^{8}$ Большой понятийный разброс свидетельствует о том, что осмысление проявлений негосударственного регулирования находится в стадии развития, что это сложный для исследователя, многослойный материал. Пестрота терминов объясняется и тем, что главенствующий в науке права догматический подход не годится для изучения негосударственных регуляторов. Тщетно стремясь разобраться в новых явлениях на основе устаревшей методологической базы, исследователи вынуждены упражняться в словообразовании.

Во избежание путаницы мы предлагаем использовать наиболее нейтральную, устоявшуюся категорию «негосударственное регулирование» для объединения регуляторов частных отношений, исходящих не от государства. Такая формулировка понятна и отражает универсальную, общую для охватываемых ею правил суть: негосударственное «авторство» и функциональная направленность на установление регулирования, «работающих» правил.

Прослеживается значительный разброс и в выделяемых видах негосударственного регулирования. Применительно к предпринимательской

\footnotetext{
${ }^{7}$ См.: Зыкин И. С. Внешнеэкономические отношения : теория и практика правового регулирования : автореф. дис. ... д-ра юрид. наук. М., 1992. С. 8 и др.

${ }^{8}$ Обзор негосударственных регуляторов в сфрере международного договорного права представлен в работе С. В. Бахина (см.: Бахин С. В. Субправо (международные своды унифицированного контрактного права). СПб., 2002. С. 87 и др.).
} 
Гражданское право. Гражданский процесс. Арбитражный процесс

среде в литературе используются следующие обобщения социальных практик: обычно-правовое регулирование, унифицированное регулирование, договорное регулирование, корпоративное регулирование, саморегулирование, биржевое регулирование, банковское регулирование, арбитражное регулирование, интернет-регулирование. Это лишь отдельные примеры, далеко не исчерпывающий (и тем более не систематизированный) перечень. Да и навряд ли можно в динамично развивающейся и меняющейся действительности зафиксировать такой перечень в актуальном состоянии. Впрочем, нет и особого смысла в его наличии. Обилие и разнообразие видов регулирования свидетельствуют о широком распространении негосударственных регуляторов в современной деловой практике, а отсутствие системности иллюстрирует то, что исследования в этой области находятся на начальной стадии. Полагаем, что здесь ученым еще предстоит сделать немало открытий.

Для правового исследования важно выявить принципы, достаточные для отнесения регулятивного массива к категории негосударственного правового регулирования. Они производны от сущностных характеристик данного вида регуляторов, которые выводятся в результате систематизации и обобщения имеющихся научных разработок.

Приниипь отнесения правила к категории негосударственного правового регулирования ложно представить в виде шести необходилых и достаточных «тестов»:

Тест 1. Частный источник (автор). Правило формируется (формулируется) частным субъектом или несколькими субъектами, юридически не наделенными властными полномочиями по изданию норм права.

Тест 2. Метод дозволительности как основа фбормирования. Субъект при формировании правила действует в режиме дозволительности, присущем частному праву, т. е. отсутствует формально возложенная законом обязанность создавать регулирование. Нормотворческое поведение является свободным выбором субъекта, проявлением его собственной воли.

Тест 3. Функииональная направленность. Цель регулирования заключена в установлении определенного порядка, правила.

Teст 4. Отсутствие государственной легитимации. Негосударственные правила не требуют непосредственного санкционирования государством для того, чтобы существовать и оказывать воздействие.

Tест 5. Отсутствие мер государственного принуждения. Действие негосударственного регулирования не опирается на меры государственного принуждения, а обеспечивается собственными механизмами, основанными на проявлениях деловой репутации и профрессиональной (отраслевой) компетенции, практичности, стремлении избежать конфликта и достичь желаемого результата при минимальных временных и материальных затратах.

Tecm 6. Правовая сущность. Несмотря на отсутствие государственного санкционирования и обеспечения, регулирование создает правовой эфрфект. 


\section{Вестник ВГУ. Серия: Право}

Мы осознаем, что характеристик у того или иного явления может быть много, и не ставим перед собой амбициозную цель перечисления и тем более анализа их всех. Это поле для отдельного исследования.

В рамках данной статьи важно выделить характеристики негосударственного правового регулирования, отличающие его от регулирования государственного, а также от регулирования в неправовом контексте. Такое понимание позволяет выстроить «мост» к основной теме нашего исследования - корпоративному регулированию как одному из проявлений негосударственного регулирования.

\section{Сущность корпоративного регулирования}

Корпоративное регулирование является одним из видов негосударственного регулирования, где источником (автором) правил выступает корпорация. Условимся под корпорацией подразумевать организацию, юридическое лицо, основанное на принципах участия (членства). Мы рассматриваем коммерческие корпорации, т. е. корпорации, деятельность которых прежде всего направлена на извлечение прибыли. Такой контекст представляется наиболее ценным для коммерческой практики, а также объясняется опорой исследования на соответствующий эмпирический материал. При этом предполагаем, что полученные результаты могут быть распространены в дальнейшем на некоммерческие организации, а также на иные объединения лиц, основанные на принципах членства (на корпорации - в широком смысле слова).

Проблемы корпоративного регулирования на современном этапе еще недостаточно емко и всесторонне освещены в российской научной литературе. Основа для таких исследований заложена в трудах Т. В. Кашаниной, О. М. Олейник, И. С. Шиткиной, В. В. Долинской, Ю. Г. Лесковой.

Ученые, каждый по-своему, творчески подходят к молодому в россий-

И. С. Шиткина делает акцент на внутренних отношениях в корпорации и ведет речь о корпоративном регулировании в узком смысле слова, имея в виду взаимоотношения между корпорацией, учредителями, участниками и членами органов корпорации ${ }^{9}$. Следует признать, что такой подход получил наибольшее распространение в российской среде ${ }^{10}$. По нашему убеждению, подобная позиция требует дополнения и расширения. Корпоративное регулирование и регулирование корпоративных отношений ни в коей мере не являются синонимами. Корпоративное регулирование, несомненно, охватывает весь спектр корпоративных отношений, но его воздействие выходит далеко за корпоративные рамки, как будет показано далее.

${ }^{9}$ См.: Корпоративное право : учебник / отв. ред. И. С. Шиткина. М., 2015. URL: http://www.consultant.ru/edu/student/download_books/book/afanaseva_eg_bak shinskas_vu_gubin_ep_shitkina_is_korporativnoe_pravo_uchebnik (дата обращения: 25.12.2019).

${ }^{10}$ См., например: Алейник С. А. Корпоративные нормы в российском праве : автореф. дис. ... канд. юрид. наук. М., 2007. 
Гражданское право. Гражданский процесс. Арбитражный процесс

Несколько шире, через призму воздействия корпоративных актов, регулирующих весь комплекс отношений в корпорации («внутри фирмы»), рассматривает корпоративное регулирование Т. В. Кашанина, отмечая, что такое регулирование адресуется учредителям, акционерам, менеджерам, наемным работникам (при этом автор уделяет особое внимание отношениям между корпорацией и работниками) ${ }^{11}$. В одном из недавних фундаментальных исследований А. Б. Козырева, суммируя ранее имевшиеся наработки, сводит корпоративное регулирование к отношениям корпорации с акционерами, управленцами и сотрудниками ${ }^{12}$.

Обзор российской доктрины по теме демонстрирует неоднородность позиций относительно содержания корпоративного регулирования, незрелость данного направления правовой науки ${ }^{13}$. Безусловно, отсутствие единого подхода к пониманию феномена корпоративного регулирования вносит неопределенность и порождает сложности в дальнейшей разработке данного направления исследований.

Российское законодательство, как и юридическая мысль, сфокусировалось на внутренних отношениях в корпорации. Не включаясь в дискуссии об их содержании и природе, такие правоотношения можно условно свести к двум видам: корпоративным правоотношениям (как правило, это отношения между корпорацией, акционерами (участниками), органами корпорации) и трудовым правоотношениям (это отношения между корпорацией и наемными работниками). Важность указанных направлений не подвергается никакому сомнению, но не только они наполняют объем корпоративного регулирования.

У практикующего юриста такое узкое толкование вызывает искреннее удивление, поскольку регулирующее воздействие, реально оказываемое корпорацией на общественные отношения, гораздо обширней.

Как объяснить повсеместно применяемые корпорациями и ими же стандартизированные процедуры преддоговорной проверки контрагентов? Почему корпорации диктуют контрагентам стандарты ведения коммерческой деятельности, ориентируют контрагентов на определенную практику подбора деловых партнеров? В силу чего потенциальный поставщик крупного производителя потребительских товаров, существенно нарушивший корпоративные правила своего покупателя, не только исключается последним из списка доверенных контрагентов, но и отторгается рынком - с ним больше никто не желает торговать? Как с позиций права оценить воздействие, оказываемое актом корпоративного регули-

${ }^{11}$ См.: Кашанина Т. В. Корпоративное право : учеб. пособие. М., 2017. С. 30-31 и др.

${ }^{12}$ См.: Козырева А. Б. Корпоративное правотворчество : теория и практика : авторефр. дис. ... канд. юрид. наук. М., 2016.

${ }^{13}$ Краткий обзор зарубежной литературы, посвященной вопросам корпоративного регулирования, представлен С. А. Чеховской. Автор показала, что, наряду с различиями во взглядах, западная мысль представляет, в целом, глубоко осмысленный опыт (см.: Чеховская C. А. «Мягкое» корпоративное право : постановка проблемы // Предпринимательское право. 2012. № 4. С. 8-12). 


\section{Вестник ВГУ. Серия: Право}

рования на отношения между контрагентом корпорации и его афффилированными лицами, деловыми партнерами и иными формально не связанными с корпорацией субъектами права?

Деловая практика свидетельствует о стремительной активизации корпоративного регулирования в центробежном направлении. Не случайно в экономической литературе корпоративное регулирование понимается через призму воздействия корпорации на ее отношения с иными лицами, т. е. как всякое регулирование, осуществляемое корпорацией. Такая позиция заслуживает поддержки, и именно она все чаще берется за основу в современных зарубежных разработках по корпоративному праву.

Чтобы объяснить эту тенденцию, уместно обратиться к экономической теории, а именно к "теории (концепции) стейкхолдеров», получившей широкое распространение и практическое применение.

В современном виде теория была сформулирована в середине 80-х гг. $\mathrm{XX}$ в. и связана с именем Э. Р. Фримена. Идея Э. Фримена состоит в том, что внешнее и внутреннее окружение корпорации (в экономическом лексиконе - фирмы) представляет собой набор лиц, реально или потенциально заинтересованных в деятельности фрирмы, интересы и запросы которых фирма должна учитывать и удовлетворять. Американский экономист разрабатывает понятие «заинтересованная сторона» (или стейкхолдер, от англ. stakeholder - держатель доли, интереса), которое впоследствии получает сотню интерпретаций. В упрощенном варианте стейкхолдер - это лицо или группа лиц, вовлеченных в деятельность корпорации, способных оказать влияние на корпорацию, или на которых влияет деятельность этой корпорация ${ }^{14}$.

Стейкхолдеры корпорации бывают внутренними и внешними.

«Внутренние стейкхолдеры» - формально и тесно связанные с корпорацией лица, непосредственно определяющие деятельность корпорации. К внутренним стейкхолдерам обычно относятся собственники бизнеса (в терминологии права - акционеры / участники), менеджеры (исполнительные органы), директора (совет директоров, наблюдательные органы), органы, осуществляющие контрольно-надзорные функции, и наем-

124 ные работники.

124 Помимо названных, корпорация взаимодействует с большим числом лиц, каждый из которых может иметь интерес (как реальный, так и потенциальный, причем не обязательно правовой или әкономический) к корпорации и ее деятельности. Это поставщики, клиенты, кредиторы, потенциальные контрагенты, аффрилированные лица и деловые партнеры контрагентов. Такие субъекты объединяются понятием «внешние стейкхолдеры» ${ }^{15}$.

${ }^{14}$ Cм.: Freeman R. E. Strategic Management: A Stakeholder Approach. Boston, 1984.

${ }^{15}$ Некоторые интерпретаторы к внешним стейкхолдерам относят также сообщества коммерсантов, местные сообщества, СМИ, группы влияния, научное сооб- 
Гражданское право. Гражданский процесс. Арбитражный процесс

Корпорация стремится упорядочить свои отношения с внешними стейкхолдерами, особенно если это крупная международная корпорация. Для этого она создает общие правила поведения, ориентированные на таких лиц, способствует их единообразному применению и следит за соблюдением своих установлений. Иными словами, корпорация взаимодействует с внешними лицами по установленным ею правилам, и желающие сотрудничать с корпорацией вынуждены следовать соответствующему порядку. В результате целенаправленной деятельности по созданию правил поведения и распространения практики их единообразного применения формируется регулирование корпорацией ее связей с окружающим миром, т. е. внешнее корпоративное регулирование. В этом заключается экономическое обоснование расширительного подхода к пониманию корпоративного регулирования ${ }^{16}$.

Пользуясь инструментарием теории стейкхолдеров, с позиций экономической науки можно дать следующее лаконичное определение корпоративного регулирования. Корпоративное регулирование - это систела воздействия корпорации на отношения с заинтересованнылми лицали (стейкхолдерали) в иелях упорядочения этих отношений.

Подводя промежуточный итог, считаем необходимым расширить наполнение понятия "корпоративное регулирование» для частноправовых исследований. Корпоративное регулирование следует понилать как вид негосударственного регулирования, осуществляелого корпорацией, действующей в режиле дозволительности, которое направлено на упорядочение частноправовых отночений, в которые вступает корпорация, путел создания юридически обязательных правил поведения, безотносительно к толу, санкиионированы и обеспечиваются они государствол или нет.

Мы определили, что в контексте направленности воздействия корпоративное регулирование может быть внутреннил и внешнил. Корпоративное регулирование может быть также индивидуальнылм и общил (нормативныл). Индивидуальное регулирование рассчитано на единичные случаи, на разовое применение, оно ориентировано на отношения корпорации с определенным субъектом. Общее (нормативное) корпоративное регулирование, напротив, имеет широкий, часто неограниченный круг адресатов, представляет правила для неоднократного использования и формирует базу для индивидуального регулирования.

Большой интерес и потенциал для исследователя представляет общее внешнее корпоративное регулирование как совершенно неизученный российской наукой права феномен. О проблеме регулирования отно-

щество, государство, межгосударственные и негосударственные международные организации и др.

${ }^{16}$ Корпоративное регулирование в широком смысле (как внешнее воздействие корпорации) подлежит доказыванию также с помощью теорий социологии и политической науки, но объем настоящей статьи не позволяет включить данное изложение. 


\section{Вестник ВГУ. Серия: Право}

шений корпорации с «субъектами внешней инфраструктуры» сообщает И. С. Шиткина ${ }^{17}$, но не развивает далее свою мысль. Крайне осторожные шаги по изучению внешнего корпоративного регулирования предпринимаются в правовой литературе: к примеру, исследуя регулирование деятельности банков, С. В. Тимофеев отмечает, что, наряду с внутренней организацией деятельности, корпоративные нормы могут «доурегулировать» уже существующие общественные отношения ${ }^{18}$. С. И. Носов предвидит, что бремя регулирования будет переходить от государства к корпоращиям, действующим в соответствующей отрасли ${ }^{19} . \kappa$ большому сожалению, далее подобных скромных замечаний отечественные исследователи не идут.

Примечательно, что совершенно противоположное происходит за рубежом. Западные юристы и представители смежных наук - социологи, политологи, экономисты - уделяют внешним проявлениям корпоративного регулирования повышенное внимание. Подтверждением тому служат новейшие публикации авторитетных издательств ${ }^{20}$, тематика научных конференций, проекты ведущих научных сообществ.

\section{Корпоративные акты}

Корпоративное регулирование в его материальном облике представлено письменно выраженными правилами поведения. В этом его отличие от обычного регулирования, объединяющего неписанный правовой материал. Письменная фиксация обычая вредит ему, лишая сути, а корпоративные установления, напротив, могут существовать только в документированном виде. Документы - неотъемлемая составляющая деятельности любой корпорации, отражение ее воли. Акты регулирующего воздействия корпорации всегда письменные.

m

${ }^{17}$ См.: Корпоративное право : учебник / отв. ред. И. С. Шиткина. Глава $5, \S 1$.

${ }^{18}$ См.: Tuлоббеев C. В. Значение локальных корпоративных актов в правовом регулировании предпринимательской деятельности банков // Вестник РГГУ. Серия: Экономика. Управление. Право. 2011. № 8. С. 84.

${ }^{19}$ См.: Носов С. И. К вопросу о природе корпоративных норм и корпоративного нормотворчества // Юрист. 2017. № 14. С. 41-46.

${ }^{20}$ Особый интерес представляют междисциплинарные исследования на стыке права и других наук, что в России случается крайне редко. Например, издательство Oxford University Press опубликовало результаты уникального правового исследования на тему частного права без государства швейцарского правоведа Т. Шульца, выполненные с опорой на методы социологии и экономики, вызвавшие бурную реакцию правового сообщества (см.: Schultz T. Transnational Legality: Stateless Law and International Arbitration. Oxford University Press, 2014). В издательстве Cambridge University Press вышла монография юриста-политолога из Канады К. Катлер, в которой детально разобрана и обоснована ведущая роль корпораций в создании негосударственного регулирования частноправовых отношений (см.: Cutler A. C. Private Power and Global Authority: Transnational Merchant Law in the Global Political Economy. Cambridge University Press, 2003). Данное исследование породило целую серию коллективных публикаций в Европе и Северной Америке, посвященных корпоративным источникам правового регулирования. 


\section{Гражданское право. Гражданский процесс. Арбитражный процесс}

Корпоративный акт - это документ корпоративного происхождения. Он принимается в соответствии с установленными в корпорации процедурами уполномоченными органами корпорации. В процедурных аспектах принятия акта требуется соблюдение нормативно-правовых предписаний, установленных государством.

В российской юриспруденции не сформировался строгий понятийный аппарат по отношению к актам, создаваемым корпорациями. В законодательстве и в правоприменительной практике встречаются следующие обозначения: «локальные акты», «внутренние документы», «корпоративные документы», «корпоративные регламенты», «акты корпораций», «нормативные акты корпораций», «автономные акты» и др. На проблему вариативности терминологии в ее актуальном состоянии обратила внимание О. М. Олейник ${ }^{21}$, об этом ранее также писали Ю. Г. Лескова ${ }^{22}$, А. Б. Козырева ${ }^{23}$ и др. Отсутствие единого подхода к обозначению всего объема документов, принимаемых корпорацией и регулирующих ее собственную деятельность и поведение связанных с ней лиц, существенно затрудняет научные исследования в данной области, поскольку ученые вынуждены всякий раз спотыкаться о терминологию и наполнять слова разным, пригодным каждому исследователю содержанием. Вполне очевидно, что должно пройти время и разрешиться не один десяток научных и судебных споров, прежде чем будет выработан простой, понятный и современный словарь корпоративно-правовой лексики.

На наш взгляд, использование лаконичного термина «корпоративные акты» для документов, автором которых выступает корпорация, существенно облегчает задачу изучения данной правовой материи. Термин был введен в научный обиход Т. В. Кашаниной для обозначения актов внутреннего корпоративного регулирования ${ }^{24}$, но ничто не препятствует его распространению на документы внешнего регулирования. Удобство заключается в том, что этот термин универсален для правовых систем и способен вместить разные по видам, названиям и регулирующей направленности документы корпорации. Систематическое использование общей категории «корпоративные акты» способствует унификации понятийного аппарата частного права и сближению правопонимания в России и за рубежом. Термином «корпоративные акты» оперируют ведущие исследователи корпоративного права О. М. Олейник, С. Ю. Филиппова, Ю. Г. Лескова, А. Б. Козырева и др.

Как и корпоративное регулирование, направленность воздействия корпоративных актов может быть внутренней и внешней.

${ }^{21}$ См.: Олейник O. М. Сфера корпоративного нормотворчества : формирование судебной практики // Закон. 2017. № 12. С. 134-141.

${ }^{22}$ См.: Лескова Ю. Г. Концептуальные и правовые основы саморегулирования предпринимательских отношений. М., 2013. С. 276-290.

${ }^{23}$ См.: Козырева А. Б. Указ. соч. С. 22-24.

${ }^{24}$ В данной статье мы не останавливаемся на всех возможных толкованиях слова «акт»: акт как действие, индивидуальный акт и пр. 


\section{Вестник ВГУ. Серия: Право}

Наиболее полно и ярко внешнее воздействие корпоративных актов проявляется в сфере договорного регулирования, ведь чаще всего корпорация вступает в деловые взаимоотношения с окружающим миром посредством договоров. Число корпоративных актов, в которых может содержаться такое регулирование, весьма значительно. Названия актов, оказывающих воздействие на договорные отношения, существенно различаются, их содержание неоднородно. Корпоративные акты могут быть представлены во множестве форм, исходить от разных органов корпорации, быть адресованы разным группам лиц и регулировать неодинаковые аспекты деятельности корпорации.

Корпоративными актами, в которых, как правило, содержится внешнее корпоративное регулирование, являются: кодексы корпоративной этики (кодексы корпоративного поведения), своды наилучших практик (best practice), регламенты, политики, правила, процедуры и рекомендации, «дорожные карты», стандартные условия договоров и другие документы. В отсутствие строгого нормативного регламентирования со стороны государства (а его и не должно быть в данной сфере) творчество корпораций в части наименований и содержательного наполнения корпоративных актов поистине не знает границ.

В качестве иллюстрации корпоративные акты крупнейшей российской розничной торговой сети X5 Retail Group, направленные на внешнее регулирование договорных отношений группы, включают следующие документы: Кодекс взаимодействия с бизнес-партнерами, Политика по работе с поставщиками товаров, предназначенных для реализации в торговых сетях X5 Retail Group, Политика по некоммерческим закупкам, Положение о работе согласительной комиссии, Условия договора поставки, приложения и дополнительные соглашения к нему (типовые формы),

м Общие условия договоров, заключаемых корпорацией, вплоть до Поло일 жения о закупке фруктов и овощей и ряда иных корпоративных актов, Z применимых к данной категории товаров ${ }^{25}$.

尺े Практически все глобальные корпорации применяют принципиально похожую модель регулирования своих договорных связей, в которой ключевая регулятивная роль отдана корпоративным актам. Менее крупные компании постепенно перенимают практику своих коллег, продемонстрировавшую наибольшую эффективность.

\section{Направления для исследования}

При подготовке данной статьи мы поставили задачу привлечь внимание юристов к проблеме негосударственного регулирования в ее новом прочтении: в виде корпоративного регулирования, обращенного вовне корпорации. Нам хотелось положить начало дискуссии в данном направлении, чтобы выявить возможные точки зрения, сопоставить ар-

25 Документы опубликованы на корпоративном сайте X5 Retail Group в сети «Интернет». URL: https://www.x5.ru/ru/Pages/Partners.aspx (дата обращения: 25.12.2019). 
Гражданское право. Гражданский процесс. Арбитражный процесс

гументацию, найти наиболее обоснованный подход. В этом видится значительный потенциал для развития научных представлений о методах негосударственного воздействия на частноправовые отношения. Результаты такого анализа могли бы быть полезны не только правовой, но и иным общественным наукам: экономике, социологии, политологии.

Исследование корпоративных регуляторов в широком смысле выступит серьезным подспорьем для практики правоприменения. Рассмотрение влияния корпоративного регулирования на договорные отношения, на наш взгляд, представляет большой интерес, анализ этой взаимосвязи может принести ценные плоды. Представители российского судейского сообщества и специалисты коммерческого арбитража сталкиваются со сложностями при принятии решений ввиду отсутствия выверенных ориентиров в части воздействия корпораций на коммерческую практику и методов правовой оценки такого воздействия. Отмечается острая необходимость в надежных источниках правовой информации, с которыми корпоративные юристы и иные занятые в бизнесе профессионалы могли бы сверяться при возникновении вопросов о корпоративном регулировании договорных связей.

Несомненно, поднятые в статье вопросы являются спорными, недостаточно изученными и требующими дальнейшего осмысления. Одной из первоочередных встает проблема правовой и нормативной природы корпоративных актов ${ }^{26}$. Наряду с изучением базовой проблематики сущности и правовой природы корпоративного регулирования, полезно было бы проследить истоки формирования и эволюцию корпоративного регулирования. Что служит движущей силой, стимулом, катализатором такого развития? Внешние факторы: биржи, банки, влиятельные кредиторы? Или экстратерриториальный эффрект государственно-правового регулирования экономически или политически более сильных стран? Возможно, истоки кроются в стремлении создать лучшее регулирование? A, может быть, причина - в защите корпорацией собственных интересов?

Как соотносятся корпоративное регулирование и корпоративное управление, корпоративное регулирование и самоуправление?

Каковы пределы корпоративного воздействия на внешних лиц? Как следует разрешать конфликты в корпоративном регулировании? Каким образом корпоративное регулирование согласуется с государственным регулированием, с иными видами негосударственного воздействия на частноправовые отношения?

Таких вопросов множество, и все они неизбежно требуют экспертного анализа. Мы искренне надеемся, что начавшийся поиск ответов окажется плодотворным.

Таким образом, на основании экономического и правового анализа предпринята попытка обосновать необходимость применения расшири-

${ }^{26}$ Наша позиция по проблеме правовой сущности корпоративного регулирования изложена в статье О. В. Фонотовой «Создает ли корпорация право? Внешнее корпоративное регулирование как правовой феномен» (Законодательство. 2019. № 9. C. 14-22). 


\section{Вестник ВГУ. Серия: Право}

тельного подхода при изучении корпоративного регулирования. На современном этапе этот вид негосударственного регулирования опосредует не только и не столько внутренние отношения, складывающиеся между корпорацией и ее акщионерами, органами и работниками, но, что особенно актуально, также и отношения корпорации с внешними субъектами: контрагентами по договорам, потенциальными деловыми партнерами, иными представителями деловой и социальной среды.

В статье отмечены точки соприкосновения корпоративного регулирования с более общей категорией негосударственного регулирования, внесено предложение терминологически обобщить массив письменного регулятивного материала корпорации единым термином «корпоративный акт», продемонстрировано значение развития исследований в области внешнего корпоративного регулирования для науки и практики и обозначены перспективные направления для дальнейшего изучения данной проблематики в частноправовом пространстве.

Национальный исследовательский университет "Высшая школа эконоликu»

Фонотова О. В., кандидат юридических наук, доцент департалента обших и межотраслевых юридических дисииплин (кафбедра международного публичного и частного права) ббакультета права

E-mail: ofonotova@hse.ru
National Research University "Higher School of Economics»

Fonotova O. V., Candidate of Legal Sciences, Associate Professor of the General and Interdisciplinary Legal Studies Department of the Faculty of Law

E-mail: ofonotova@hse.ru 